(2) Open Access Full Text Article

REVIEW

\title{
Interest in paromomycin for the treatment of visceral leishmaniasis (kala-azar)
}

This article was published in the following Dove Press journal:

Therapeutics and Clinical Risk Management

21 June 2012

Number of times this article has been viewed

\author{
Viroj Wiwanitkit ${ }^{1-3}$ \\ 'Wiwanitkit House, Bang Khae, \\ Bangkok, Thailand; ${ }^{2}$ Hainan Medical \\ University, Haikou, Hainan, People's \\ Republic of China; ${ }^{3}$ Joseph Ayo \\ Babalola University, Ikeji-Arakeji, \\ Osun State, Nigeria
}

\begin{abstract}
Leishmaniasis is an important vector-borne disease, and it is classified as one of the most important tropical fly-borne infections. This disease can cause two types of clinical manifestations: cutaneous forms and visceral forms. Visceral leishmaniasis, which is also called kala-azar, is a very serious infection that can be fatal. The management of visceral leishmaniasis requires informed diagnostic and therapeutic approaches. Continuous research and development regarding the treatment of visceral leishmaniasis had led to many improvements. Paromomycin is a relatively new antibiotic drug that has been used for the treatment of visceral leishmaniasis for several years. This article reviews and discusses the use of paromomycin for visceral leishmaniasis therapy.
\end{abstract}

Keywords: visceral, leishmaniasis, paromomycin

\section{Introduction}

Leishmaniasis is an important parasitic infection of the blood. It is classified as a protozoan disease, and it is caused by Leishmania spp. Leishmaniasis is found in many countries throughout the world, and it is classified as an important vector-borne infection. The transmission of disease is via a vector: in this case, the bite of a fly. Leishmaniasis transmission can be from an infected human or animal (especially a canine) to another human..$^{1-3}$ There are two important groups of problematic sand flies: genus Phlebotomus in undeveloped countries, and genus Lutzomyia in more developed areas. ${ }^{1-5}$ As a result of the nature of vector-borne diseases, vector control is the focus of disease control. ${ }^{6}$ It is estimated that more than 1 million new cases of leishmaniasis occur each year. ${ }^{7}$ At present, leishmaniasis is classified as an important neglected tropical disease. ${ }^{8}$ The disease is highly prevalent in many poor and developing countries. In addition, the extension of the disease into new settings has been reported for the past two decades. ${ }^{89}$ Hence, leishmaniasis is currently a disease of global concern. Another important problem involving the control of leishmaniasis is the difficulty of treating this disease. The problem of drug resistance has emerged in many endemic areas. In recent years, some new drugs have been introduced to fight drug-resistant leishmaniasis. The aim of this article is to provide a critical review of the treatment of visceral leishmaniasis with the new drug paromomycin. This article will discuss several specific aspects of the drug, including both its benefits and its side effects.

\section{Clinical aspects of visceral leishmaniasis}

Leishmaniasis is an important vector-borne disease, and it is classified as one of the most important tropical fly-borne infections. This disease can cause two types of 
clinical manifestations: cutaneous forms ${ }^{10-12}$ and visceral forms. ${ }^{13-15}$ The reticuloendothelial system, the spleen, and the liver are the main parts of the body that are affected by visceral leishmaniasis. ${ }^{13-15}$ In approximately $10 \%$ of cases, some additional bone marrow involvement can be observed. ${ }^{1,2}$ The disease can be both chronic and deadly. Patients usually experience a delay before diagnosis and treatment. Visceral leishmaniasis is common in immunocompromised hosts; thus, it is a focused disease that is currently under surveillance for immunocompromised patients. ${ }^{16}$ With regard to the epidemiology of visceral leishmanaisis, the endemic areas include the Middle East and South Asia. ${ }^{13-15}$ Visceral leishmaniasis was previously limited to these endemic areas. However, the emergence of the disease in new settings has been continuously reported for several years. ${ }^{8,9}$ The migration of disease is an important issue in modern travel medicine.

The diagnosis of visceral leishmaniasis can be difficult, and it is often delayed. In endemic areas, most diagnoses are usually derived from the microscopic examination of tissue smears. ${ }^{14}$ Better serology and molecular methods are usually not available as a result of resource limitation. ${ }^{14}$ The management of visceral leishmaniasis still requires good diagnostic and therapeutic approaches. Continuous research and development regarding the treatment of visceral leishmaniasis is needed. At present, the treatment for visceral leishmaniasis requires long courses of medication and parenteral administration. ${ }^{13}$ The cost of treatment is considered quite expensive in resource-limited settings. ${ }^{13}$ There is no doubt that medication and medical care are the two main factors that affect the cost-effectiveness ranking of the selection of new treatment. ${ }^{17}$ Nevertheless, research and development regarding the treatment of visceral leishmaniasis has led to many improvements. ${ }^{18}$ It is hoped that the use of these new drugs will lead to the complete elimination of visceral leismaniasis. ${ }^{19}$ In addition, active case-finding and vector-control strategies should not be overlooked; these activities remain very significant for the successful control of visceral leishmaniasis. ${ }^{20}$

\section{Why do we need a new drug for the treatment of visceral leishmaniasis?}

Visceral leishmaniasis is classified as a treatable disease. Early diagnosis and treatment are important to the successful management of patients. With regard to treatment, medical therapy with the use of an antileishmanial drug is the key approach. Antileishmanial drugs have been used for the treatment of visceral leishmaniasis for a long time. However, as time passes, problems with old drugs are detected, and new drugs are needed (Table 1). The classical treatment, which is based on a pentavalent antimony complex, involves frequent drug resistance. ${ }^{13,14}$ There are many problems with the current treatment of visceral leishmaniasis treatment. These problems lead to poor outcomes of the treatment in general. However, the main concern is the drug treatment.

Problems with drug treatment are common in settings where disease incidence is high. For example, in India, where visceral leishmaniasis is highly prevalent, the problem of drug resistance is common. ${ }^{14}$ The first classical drug, antimony, is already useless as a result of drug resistance, and has not been used since the $1970 \mathrm{~s} .{ }^{21}$ A report by Olliaro et al concluded that "unresponsiveness to antimony has developed steadily in the past to such an extent that antimony must now be replaced, despite attempts to stop its progression by increasing dose and duration of therapy." ${ }^{22}$

The second-line drugs pentamidine and amphotericin B remain effective, but their use is limited as a result of toxicity and availability. ${ }^{13,14}$ Both pentamidine and amphotericin B are more effective for getting rid of the parasites than the classical pentavalent antimony complex. As compared with amphotericin B, pentamidine is easier to use, it has fewer side effects, and it is not light sensitive; hence, it is more widely used. However, the problem of drug resistance is also observed with pentamidine. The failure rate of pentamidine use has been reported to be as high as 33\% in India; this has led to the conclusion that this drug is not particularly useful, and the increasing or doubling of the dose is routinely required. ${ }^{23}$ A combination of drugs is also used for

Table I Problems associated with the classical antileishmanial drugs

\begin{tabular}{|c|c|c|}
\hline Drugs & Problems & Details \\
\hline Pentavalent antimony complex ${ }^{1-3}$ & Drug resistance & $\begin{array}{l}\text { Nearly } 100 \% \text { of the cases in endemic areas such as India do not respond } \\
\text { to pentavalent antimony. }{ }^{3}\end{array}$ \\
\hline Pentamidine $^{4}$ & Drug resistance & $\begin{array}{l}\text { One-third of the cases in endemic areas, especially in India, require the double dosage } \\
\text { of pentamidine for effective treatment. }{ }^{4}\end{array}$ \\
\hline Sodium stibogluconate ${ }^{5}$ & Drug resistance & $\begin{array}{l}\text { In India, the failure of treatment with sodium stibogluconate has increased, and } \\
\text { in vitro and in vivo studies of parasite isolates confirm this refractoriness. }\end{array}$ \\
\hline Amphotericin $\mathrm{B}^{1,2}$ & Cost; toxicity & $\begin{array}{l}\text { The high cost and high toxicity of amphotericin B are the major problems that lead } \\
\text { to this drug not being widely used. }{ }^{1,2}\end{array}$ \\
\hline
\end{tabular}


the treatment of leishmaniasis; however, its effectiveness has not been confirmed. ${ }^{24-26}$ In addition, newer drugs (eg, new lipid formulations of amphotericin B, the new oral drug miltefosine) have been licensed for a few years, but the main problem with these is their cost. ${ }^{13,14} \mathrm{~A}$ similar situation is also observed with the use of sodium stibogluconate therapy. ${ }^{27}$ With all of this information in mind, there is no doubt that new drugs for visceral leishmaniasis treatment are required.

\section{A new drug for the treatment of leishmaniasis: paromomycin}

Paromomycin is an antibiotic drug that was introduced for the treatment of visceral leishmaniasis in 2006. It is classified as a new aminoglycoside antibiotic. Paromomycin originated from the bacterial pathogen Streptomyces rimosus var. paromomycinus. It is considered a broad-spectrum antibiotic, and it is also used for the treatment of parasitic infestation. ${ }^{28}$ With regard to pharmaceutical information, ${ }^{29-33}$ paromomycin is an aminoglycoside antibiotic. It was first discovered during the 1950s, and it exists as paromomycin sulfate. It is a white and amorphous product. Paromomycin is stable and water soluble. It has been reported that paromomycin can bear heat up to $120^{\circ} \mathrm{C}$ for 24 hours. However, if it is exposed to heat of $130^{\circ} \mathrm{C}$, degradation can be seen, and it loses a third of its biological activity. ${ }^{34}$ The chemical composition of paromomycin sulfate is $0-2$, 6-diamino-2, 6 -dideoxy- $\beta$-L-idopyranosyl- $(1 \rightarrow 3)-0$ - $\beta$-D-ribofuranosyl$(1 \rightarrow 5)$-0-[2-amino-2-deoxy- $\alpha$-D-glucopyranosyl- $(1 \rightarrow 4)]$ 2-deoxystreptamine sulfate salt. The molecular formula is $\mathrm{C} 23 \mathrm{H} 45 \mathrm{~N} 5 \mathrm{O} 14 \mathrm{xH} 2 \mathrm{SO} 4$, and the molecular weight is equal to 615.64. The classical available form of paromomycin in medical marketing is the paromomycin sulfate capsule, and the brand name is Humatin ${ }^{\circledR}$ (Caraco Pharmaceutical Laboratories, Ltd, Detroit, MI). The paromomycin capsule is for oral intake, and each one contains $250 \mathrm{mg}$. The newer form of paromomycin, the injection form, was successfully pharmaceutically produced. It is mainly given as an intramuscular injection. This form is widely used for systemic infection. An ointment form has also been prepared for the treatment of local skin infections. ${ }^{35}$ Finally, the inhalation form of paromomycin has recently been produced, and it is also indicated for the treatment of some systemic infections (eg, cryptosporidiosis). ${ }^{36}$ The indications for the usage of each form of paromomycin are different (Table 2).

With regard to pharmacokinetics and pharmacodynamics, both the in vitro and in vivo antibacterial actions of paromomycin are high. The drug is as highly effective as neomycin. However, the classical oral form poses the
Table 2 Forms of paromomycin and their clinical usage

\begin{tabular}{ll}
\hline Forms & Examples of indications \\
\hline Orall $^{-3}$ & Amebiasis; cryptosporidiosis; tapeworm infestations \\
Ointment $^{4}$ & Trichomoniasis; cutaneous leishmaniasis \\
Inhalation $^{5}$ & Cryptosporidiosis \\
Injection $^{6}$ & Drug-resistant tuberculosis; visceral leishmaniasis \\
\hline
\end{tabular}

problem of absorption. After oral administration, almost all of the drug cannot be effectively absorbed, and nearly all of the drug is recoverable from the stool; hence, it is useful for the treatment of intestinal infection. With long-term, highdose treatment, there is also no systematic absorption of oral paromomycin. ${ }^{37}$ Paromomycin is considered active against several Gram-negative and Gram-positive bacteria, and it is also active against some protozoa and cestodes. At first, paromomycin was indicated for intestinal amebiasis, ${ }^{38-40}$ and its usage was later expanded for many other infections, including visceral leishmaniasis. Although paromomycin is considered a broad-spectrum antibiotic, it does not affect the pattern of useful intestinal microflora. Iwaki et al reported that, "after administration was discontinued, reduced bowel flora was returned to the normal range within a few days." 41 For the injection form of the drug, the pharmacokinetics study revealed that the peak concentration of paromomycin can be derived 2 hours after administration, and the drug is completely eliminated within 24 hours. ${ }^{42}$ The elevation of blood urea and blood urea nitrogen can be observed after an intramuscular injection dose of $90 \mathrm{mg} / \mathrm{kg}$. ${ }^{43}$ The inhibition of protein synthesis by binding to $16 \mathrm{~S}$ ribosomal RNA is the main drug action. ${ }^{43}$ Fourmy et al reported that paromomycin binding resulted in a local conformational change in the A site of $16 \mathrm{~S}$ ribosomal RNA. ${ }^{44}$ The detected changes at the N1 positions of A1492 and A1493 on the minor groove side of the A-site RNA implied a mechanism of action that occurred during translation. ${ }^{44}$ In conclusion, the main action of paromomycin is the inhibition of translation..$^{44,45}$

It is generally recommended that paromomycin be used for the treatment or prevention of infections that are proven to be caused by a susceptible pathogen. This reduces the chance of the development of drug-resistant bacteria, and it maintains the effectiveness of the drug. Paromomycin is contraindicated for those patients with a history of previous hypersensitivity reactions (eg, drug allergy) and intestinal obstruction (for the oral form). Cross reactivity to neomycin can be seen, and this is an important precaution to remember when using paromomycin. ${ }^{46}$ The standard dosage for oral paromomycin is 25 to $35 \mathrm{mg}$ per kilogram of body weight daily. The administration of the 
drug should be done in three divided doses with meals, and the use of the drug should be continuous for 5 to 10 days. Some adverse reactions or side effects of paromomycin can be seen; the important ones include nausea, abdominal cramps, and diarrhea. The chance of developing a side effect significantly increases in any patients who receive a dose of more than $3 \mathrm{~g}$ per day.

Recently, advancements in pharmacology have allowed for the development of a newer modified version of paromomycin. The so-called "paromomycin-loaded albumin microsphere" has been in use for a few years. The preparation of paromomycin-loaded albumin microspheres (ie, $<5 \mu \mathrm{m}$ ) helps to better target macrophages for treatment. This is useful for the treatment of leishmaniasis. ${ }^{47}$ Khan et al reported that "pharmacokinetic studies demonstrated nearly $80 \%$ reduction in $\mathrm{C}_{(\max )}$ of paromomycin when administered as paromomycin-loaded albumin microsphere, compared to other formulations at equivalent dose. ${ }^{\prime 3}$ In addition, it has been observed that there are no symptoms of toxicity with the use of paromomycin-loaded albumin microspheres at the level that was reported to be toxic for classical paromomycin. ${ }^{43}$ According to a clinical trial by Thakur et al, it has been confirmed that injectable paromomycin is effective and safe for the treatment of patients with visceral leishmaniasis. ${ }^{48}$

\section{Efficacy of paromomycin in the treatment of leishmaniasis}

Paromomycin, which was introduced in 2006, can be thought of as a new candidate for the treatment of leishmaniasis. ${ }^{49-51}$ Sundar and Chakravarty stated that "paromomycin, with its excellent efficacy, low cost, shorter duration of administration and good safety profile, has the potential to be used as a first-line drug. ${ }^{52}$ Indeed, based on the nature of broadspectrum antibiotics as previously described, paromomycin is useful for the treatment of many infections. For the treatment of leishmaniasis, paromomycin is one of two new recommended drugs, in addition to miltefosine, which was introduced in 2002..$^{53}$

For visceral leishmaniasis, a paromomycin intramuscular injection can be effectively used. It can also be effective for patients with resistance to other drugs, including sitamaquine. ${ }^{54}$ There are many recent trials, in both animals and humans, that have looked at the treatment of visceral leishmaniasis with paromomycin. The pioneering study of the effects of paromomycin on visceral leishmaniasis in rats was reported by Buffet et al. ${ }^{55}$ In this study, a good efficacy of paromomycin was observed; this study was the origin for the further development of this drug for visceral leishmaniasis treatment. A continuous study by Williams et al in a rat model also confirmed the antileishmanial activity of the drug both in vitro and in vivo. ${ }^{56}$ The effectiveness of the widely used injection regimen has also been confirmed for humans. ${ }^{48}$ Chunge et al studied several regimens for the treatment of visceral leishmaniasis and concluded that "treatment with aminosidine [paromomycin] alone was the cheapest and safest regime." ${ }^{57}$ A 21-day course of $20 \mathrm{mg}$ per kilogram of body weight per day should be used as first-line treatment for visceral leishmaniasis. ${ }^{58-61}$ A reduction of liver and spleen size can be observed an average of 2 years after treatment, and the weight gain seen among patients taking this drug is a sign of a good response. ${ }^{61}$ Generally, the complete disappearance of the parasite can be seen 6 to 7 months after drug administration. ${ }^{62}$ The efficacy of paromomycin is equal to that of amphotericin B. It has also been noted that paromomycin is not inferior to amphotericin B. ${ }^{63}$ The severe adverse effects, especially nephrotoxicity and fever, are significantly lower in patients who are receiving paromomycin as compared with those who are receiving amphotericin B. ${ }^{63}$ Nevertheless, some adverse effects (eg, the elevation of liver enzymes, pain at the infection site) are more common among patients who are receiving paromomycin. ${ }^{63,64}$ In addition, dermal leishmaniasis after visceral leishmaniasis has also been reported as a cutaneous manifestation after treatment. ${ }^{65}$

It should be noted that paromomycin is considered costeffective from a pharmacoeconomic perspective. On the basis of a recent assessment from India, it has been reported that "paromomycin is the cheapest option $(\$ 7450$ to treat 1000 patients)." ${ }^{66}$ This is equal to "US\$2 for paromomycin in an outpatient setting." ${ }^{97}$ Nevertheless, paromomycin monotherapy poses a risk for the development of drug resistance. ${ }^{68}$ Therefore, the use of combination therapy is recommended for the management of visceral leishmaniasis that is aiming at successful control. Banerjee et al concluded that, "once the elimination target of one case per 10,000 population has been reached, combination therapies involving miltefosine and paromomycin can be introduced to ensure long-term availability of several drugs for visceral leishmaniasis and to protect against resistance." ${ }^{\prime 69}$

As noted previously, newer, modified paromomycin given via the liposome technique is also available for the treatment of visceral lesihmaniasis. ${ }^{68}$ Paromomycinassociated stearylamine-bearing liposome is the best example of this. ${ }^{70}$ 


\section{Future trends in the use of paromomycin for the treatment of visceral leishmaniasis}

There can be no doubt that paromomycin will be used worldwide for the treatment of visceral leishmaniasis as a result of its good effectiveness. However, the problem of drug resistance will continue to grow if there is no control of appropriate, rational usage. The continuum for the development of a new generation of paromomycin involves the hope for a better and safer drug for the management of visceral leishmaniasis.

\section{Conclusion}

Paromomycin is an old antibiotic that has been newly approved for use in the treatment of leishmaniasis. The use of paromomycin treatment has been confirmed for its efficacy and safety in the management of patients with visceral leishmaniasis. This drug is inexpensive, and it has been accepted as a first-line alternative drug in the setting of resistance to classical antileishmanial drugs.

\section{Disclosure}

The author reports no conflicts of interest in this work.

\section{References}

1. Wiwanitkit V, Singh MY. Emerging Infectious Diseases in India. New York: Nova Publisher; 2008.

2. Wiwanitkit V. Bone marrow leishmaniasis: a review of situation in Thailand. Asian Pac J Trop Med. 2011;4(10):757-759.

3. Antinori S, Schifanella L, Corbellino M. Leishmaniasis: new insights from an old and neglected disease. Eur J Clin Microbiol Infect Dis. 2012;31(2):109-118

4. Grimaldi G Jr, Tesh RB, McMahon-Pratt D. A review of the geographic distribution and epidemiology of leishmaniasis in the New World. Am J Trop Med Hyg. 1989;41(6):687-725.

5. Grimaldi G Jr, McMahan-Pratt D. Leishmaniasis and its etiologic agents in the New World: an overview. Prog Clin Parasitol. 1991;2: 73-118.

6. Hamilton JG. Sandfly pheromones. Their biology and potential for use in control programs. Parasite. 2008;15(3):252-256.

7. Desjeux P. Leishmaniasis: current situation and new perspectives. Comp Immunol Microbiol Infect Dis. 2004;27(5):305-318.

8. Alvar J, Yactayo S, Bern C. Leishmaniasis and poverty. Trends Parasitol. 2006;22(12):552-557.

9. Marinkelle CJ. The control of leishmaniases. Bull World Health Organ. 1980;58(6):807-818.

10. Hepburn NC. Cutaneous leishmaniasis: an overview. J Postgrad Med. 2003;49(1):50-54.

11. Hepburn NC. Cutaneous leishmaniasis. Clin Exp Dermatol. 2000;25(5):363-370.

12. Enk CD, Gardlo $\mathrm{K}$, Hochberg $\mathrm{M}$, Ingber $\mathrm{A}$, Ruzicka T. Cutaneous leishmaniasis. Hautarzt. 2003;54(6):506-512.

13. Guerin PJ, Olliaro P, Sundar S, et al. Visceral leishmaniasis: current status of control, diagnosis, and treatment, and a proposed research and development agenda. Lancet Infect Dis. 2002;2(8):494-501.

14. Singh RK, Pandey HP, Sundar S. Visceral leishmaniasis (kala-azar): challenges ahead. Indian J Med Res. 2006;123(3):331-344.
15. Herwaldt BL. Leishmaniasis. Lancet. 1999;354(9185):1191-1199.

16. Ali A. Leishmaniases and HIV/AIDS co-infections: review of common features and management experiences. Ethiop Med J. 2002;40(Suppl 1): $37-49$.

17. Vanlerberghe V, Diap G, Guerin PJ, et al. Drug policy for visceral leishmaniasis: a cost-effectiveness analysis. Trop Med Int Health. 2007;12(2):274-283.

18. Murray HW. Progress in the treatment of a neglected infectious disease: visceral leishmaniasis. Expert Rev Anti Infect Ther. 2004;2(2):279-292.

19. Matlashewski G, Arana B, Kroeger A, et al. Visceral leishmaniasis: elimination with existing interventions. Lancet Infect Dis. 2011;11(4):322-325.

20. Mondal S, Bhattacharya P, Ali N. Current diagnosis and treatment of visceral leishmaniasis. Expert Rev Anti Infect Ther. 2010;8(8): 919-944.

21. Jha TK. Drug unresponsiveness and combination therapy for kala-azar. Indian J Med Res. 2006;123:389-398.

22. Olliaro PL, Guerin PJ, Gerstl S, Haaskjold AA, Rottingen JA, Sundar S. Treatment options for visceral leishmaniasis: a systematic review of clinical studies done in India, 1980-2004. Lancet Infect Dis. 2005;5(12):763-774.

23. Sundar S. Drug resistance in Indian visceral leishmaniasis. Trop Med Int Health. 2001;6(11):849-854.

24. Olliaro PL. Drug combinations for visceral leishmaniasis. Curr Opin Infect Dis. 2010;23(6):595-602.

25. Meheus F, Balasegaram M, Olliaro P, et al. Cost-effectiveness analysis of combination therapies for visceral leishmaniasis in the Indian subcontinent. PLoS Negl Trop Dis. 2010;4(9):pii:e818.

26. van Griensven J, Boelaert M. Combination therapy for visceral leishmaniasis. Lancet. 2011;377(9764):443-444.

27. Dube A, Singh N, Sundar S, Singh N. Refractoriness to the treatment of sodium stibogluconate in Indian kala-azar field isolates persist in in vitro and in vivo experimental models. Parasitol Res. 2005;96(4):216-223.

28. Liu LX, Weller PF. Antiparasitic drugs. N Engl J Med. 1996;334(18) $1178-1184$.

29. Paromomycin preparations. Jpn J Antibiot. 1983;36(3):644-649.

30. Simon HJ. Streptomycin, kanamycin, neomycin and paromomycin. Pediatr Clin North Am. 1968;15(1):73-83.

31. Mössner G. Therapy of intestinal infections with paromomycin Pharmakotherapia. 1964;2(1):149-164.

32. Münchow P. New ready-made drugs. 9. Paromomycin "Jenapharm." Pharm Prax. 1965;9:211-213.

33. Davidson RN, den Boer M, Ritmeijer K. Paromomycin. Trans R Soc Trop Med Hyg. 2009;103(7):653-660.

34. Khan W, Kumar N. Characterization, thermal stability studies, and analytical method development of paromomycin for formulation development. Drug Test Anal. 2011;3(6):363-372.

35. Nyirjesy P, Sobel JD, Weitz MV, Leaman DJ, Gelone SP. Difficult-totreat trichomoniasis: results with paromomycin cream. Clin Infect Dis. 1998;26(4):986-988.

36. de la Tribonnière X, Valette $\mathrm{M}$, Alfandari S. Oral nitazoxanide and paromomycin inhalation for systemic cryptosporidiosis in a patient with AIDS. Infection. 1999;27(3):232.

37. Bissuel F, Cotte L, de Montclos M, Rabodonirina M, Trepo C. Absence of systemic absorption of oral paromomycin during longterm, high-dose treatment for cryptosporidiosis in AIDS. J Infect Dis. 1994;170(3):749-750

38. Stauffer W, Ravdin JI. Entamoeba histolytica: an update. Curr Opin Infect Dis. 2003;16(5):479-485.

39. Wolfe MS. The treatment of intestinal protozoan infections. Med Clin North Am. 1982;66(3):707-720.

40. Botero D. Chemotherapy of human intestinal parasitic diseases. Annu Rev Pharmacol Toxicol. 1978;18:1-15.

41. Iwaki S, Honke K, Nishida N, Taniguchi N. The absorption, excretion and influence on bowel flora of oral paromomycin sulfate (author's trans1). Jpn J Antibiot. 1981;34(7):1078-1081. 
42. Kanyok TP, Killian AD, Rodvold KA, Danziger LH. Pharmacokinetics of intramuscularly administered aminosidine in healthy subjects. Antimicrob Agents Chemother. 1997;41(5):982-986.

43. Khan W, Sharma SS, Kumar N. Bioanalytical method development, pharmacokinetics, and toxicity studies of paromomycin and paromomycin loaded in albumin microspheres. Drug Test Anal. March 22, 2012. [Epub ahead of print.]

44. Fourmy D, Yoshizawa S, Puglisi JD. Paromomycin binding induces a local conformational change in the A-site of $16 \mathrm{~S}$ rRNA. J Mol Biol. 1998;277(2):333-345.

45. Eustice DC, Wilhelm JM. Mechanisms of action of aminoglycoside antibiotics in eucaryotic protein synthesis. Antimicrob Agents Chemother. 1984;26(1):53-60.

46. Pirila V, Rouhunkoski S. The pattern of cross-sensitivity to neomycin. 51 cases of secondary sensitization to paromomvcin (Humatin). Dermatologica. 1962;125:273-278.

47. Khan W, Kumar N. Drug targeting to macrophages using paromomycinloaded albumin microspheres for treatment of visceral leishmaniasis: an in vitro evaluation. J Drug Target. 2011;19(4):239-250.

48. Thakur CP, Kanyok TP, Pandey AK, Sinha GP, Messick C, Olliaro P. Treatment of visceral leishmaniasis with injectable paromomycin (aminosidine). An open-label randomized phase-II clinical study. Trans R Soc Trop Med Hyg. 2000;94(4):432-433.

49. Croft SL, Olliaro P. Leishmaniasis chemotherapy - challenges and opportunities. Clin Microbiol Infect. 2011;17(10):1478-1483.

50. Mondal S, Bhattacharya P, Ali N. Current diagnosis and treatment of visceral leishmaniasis. Expert Rev Anti Infect Ther. 2010;8(8): 919-944.

51. Janvier F, Morillon M, Olliaro P. Visceral leishmaniasis: clinical sensitivity and resistance to various therapeutic agents. Med Trop (Mars). 2008;68(1):89-101.

52. Sundar S, Chakravarty J. Paromomycin in the treatment of leishmaniasis. Expert Opin Investig Drugs. 2008;17(5):787-794.

53. Croft SL, Sundar S, Fairlamb AH. Drug resistance in leishmaniasis. Clin Microbiol Rev. 2006;19(1):111-126.

54. Kulshrestha A, Singh R, Kumar D, Negi NS, Salotra P. Antimonyresistant clinical isolates of Leishmania donovani are susceptible to paromomycin and sitamaquine. Antimicrob Agents Chemother. 2011;55(6):2916-2921.

55. Buffet PA, Garin YJ, Sulahian A, Nassar N, Derouin F. Therapeutic effect of reference antileishmanial agents in murine visceral leishmaniasis due to Leishmania infantum. Ann Trop Med Parasitol. 1996;90(3):295-302.

56. Williams D, Mullen AB, Baillie AJ, Carter KC. Comparison of the efficacy of free and non-ionic-surfactant vesicular formulations of paromomycin in a murine model of visceral leishmaniasis. $J$ Pharm Pharmacol. 1998;50(12):1351-1356.
57. Chunge CN, Owate J, Pamba HO, Donno L. Treatment of visceral leishmaniasis in Kenya by aminosidine alone or combined with sodium stibogluconate. Trans R Soc Trop Med Hyg. 1990;84(2):221-225.

58. Jha TK, Olliaro P, Thakur CP, et al. Randomised controlled trial of aminosidine (paromomycin) v sodium stibogluconate for treating visceral leishmaniasis in North Bihar, India. BMJ. 1998;316(7139):1200-1205.

59. Olliaro PL, Guerin PJ, Gerstl S, Haaskjold AA, Rottingen JA, Sundar S. Treatment options for visceral leishmaniasis: a systematic review of clinical studies done in India, 1980-2004. Lancet Infect Dis. 2005;5(12):763-774.

60. Sundar S, Agrawal N, Arora R, Agarwal D, Rai M, Chakravarty J. Short-course paromomycin treatment of visceral leishmaniasis in India: 14-day vs 21-day treatment. Clin Infect Dis. 2009;49(6):914-918.

61. Castro C, Macêdo V, Silva-Vergara ML, et al. Effectiveness of aminosidine sulphate in severe visceral leishmaniasis, resistant to the treatment with pentavalent antimony. Rev Soc Bras Med Trop. 1995;28(3):273-277.

62. Sundar S, Jha TK, Thakur CP, Sinha PK, Bhattacharya SK. Injectable paromomycin for visceral leishmaniasis in India. $N$ Engl $J$ Med. 2007;356(25):2571-2581.

63. Musa AM, Younis B, Fadlalla A, et al. Paromomycin for the treatment of visceral leishmaniasis in Sudan: a randomized, open-label, dosefinding study. PLoS Negl Trop Dis. 2010;4(10):e855.

64. Sinha PK, Jha TK, Thakur CP, et al. Phase 4 pharmacovigilance trial of paromomycin injection for the treatment of visceral leishmaniasis in India. J Trop Med. 2011;2011:645203.

65. Pandey K, Das VN, Singh D, et al. Post-kala-azar dermal leishmaniasis in a patient treated with injectable paromomycin for visceral leishmaniasis in India. J Clin Microbiol. 2012;50(4):1478-1479.

66. Olliaro P, Sundar S. Anthropometrically derived dosing and drug costing calculations for treating visceral leishmaniasis in Bihar, India. Trop Med Int Health. 2009;14(1):88-92.

67. Olliaro P, Darley S, Laxminarayan R, Sundar S. Cost-effectiveness projections of single and combination therapies for visceral leishmaniasis in Bihar, India. Trop Med Int Health. 2009;14(8):918-925.

68. Matlashewski G, Arana B, Kroeger A, et al. Visceral leishmaniasis: elimination with existing interventions. Lancet Infect Dis. 2011;11(4): 322-325.

69. Banerjee A, De M, Ali N. Combination therapy with paromomycinassociated stearylamine-bearing liposomes cures experimental visceral leishmaniasis through Th1-biased immunomodulation. Antimicrob Agents Chemother. 2011;55(4):1661-1670.

70. Banerjee A, De M, Ali N. Complete cure of experimental visceral leishmaniasis with amphotericin B in stearylamine-bearing cationic liposomes involves down-regulation of IL-10 and favorable T cell responses. J Immunol. 2008;181(2):1386-1398.
Therapeutics and Clinical Risk Management

\section{Publish your work in this journal}

Therapeutics and Clinical Risk Management is an international, peerreviewed journal of clinical therapeutics and risk management, focusing on concise rapid reporting of clinical studies in all therapeutic areas, outcomes, safety, and programs for the effective, safe, and sustained use of medicines. This journal is indexed on PubMed Central, CAS,

\section{Dovepress}

EMBase, Scopus and the Elsevier Bibliographic databases. The manuscript management system is completely online and includes a very quick and fair peer-review system, which is all easy to use. Visit http://www.dovepress.com/testimonials.php to read real quotes from published authors. 